\title{
Connexin 32 expression reduces malignant phenotype in human A549 adenocarcinoma cells: Implication of Src involvement
}

\author{
SACHIO HADA ${ }^{1,2}$, HIROMI SATO ${ }^{1}$, NANTIGA VIRGONA ${ }^{1}$, HIROMI HAGIWARA ${ }^{1,3}$, \\ TERUNOBU SAITO $^{1,2}$, KAZUYUKI SUZUKI ${ }^{2}$, RYUJI ASANO ${ }^{2}$ and TOMOHIRO YANO ${ }^{1}$ \\ ${ }^{1}$ Department of Food Science Research for Health, National Institute of Health and Nutrition, 1-23-1 Toyama, \\ Shinjuku-ku, Tokyo 162-8636, ${ }^{2}$ Department of Veterinary Pharmacology, Nihon University College of \\ Bioresource Sciences, Kanagawa 252-8510, ${ }^{3}$ Japan Health Sciences Foundation, Chuo, Tokyo 103-0001, Japan
}

Received May 8, 2006; Accepted July 31, 2006

\begin{abstract}
Recent evidence suggests that a member of the gap junction protein family, connexin $(\mathrm{Cx}) 32$, acts as a tumor suppressor gene against lung adenocarcinoma. However, the precise mechanism remains unclear. In this study, we tried to explore the mechanism for the Cx32-dependent tumorsuppressive effect in lung adenocarcinoma. To perform this study, we established a stable clone of the human lung adenocarcinoma cell line, A549 in which the Cx32 gene was expressed. Cx32 expression in A549 cells reduced anchorageindependent growth and development of tumors in a xenograft model. Additionally, Cx32 induced contact inhibition of growth and reduced invasive activity in A549 cells. The tumor-suppressive effects of $\mathrm{Cx} 32$ depended on the inhibition of Src activity. These events were confirmed by an Src inhibitor (PP1) and siRNA for Cx32. These results suggest that the Cx32-dependent tumor-suppressive effect in A549 cells is explained by the inhibition of Src activity.
\end{abstract}

\section{Introduction}

Gap junctional intercellular communication (GJIC) has been considered the only route allowing direct transfer of small metabolites between cells to maintain homeostasis in multicellular organisms (1). The gap junction is made up of juxtaposed transmembrane hemichannels (connexons) provided by adjacent cells where each connexon consists of six connexin (Cx) protein subunits (2). So far, cDNAs from at least 20 different $\mathrm{Cx}$ molecules have been cloned in humans (3). Different combinations of Cx molecules in different tissues contribute to cell differentiation and cell growth control (4).

Correspondence to: Dr Tomohiro Yano, Department of Food Science Research for Health, National Institute of Health and Nutrition, 1-23-1 Toyama, Shinjuku-ku, Tokyo 162-8636, Japan

E-mail: yano@nih.go.jp

Key words: connexin 32, lung adenocarcinoma, Src, adherence junctions, fibrinolytic factors
Vast lines of evidence strongly support the hypothesis that $\mathrm{Cx}$ genes act as tumor-suppressor genes (5). Tumor-promoting agents and oncogenes disrupt CX-mediated GJIC, whereas anti-tumor agents such as retinoids up-regulate the GJIC (6). Decreased or diminished expression and function of $\mathrm{Cx}$ genes are usually observed in most tumor cells $(7,8)$. Furthermore, cells derived from the Cx43 gene knockout mice had a higher tendency for tumorigenesis compared to those of the wild-type (9). More direct evidence for the tumorsuppressive effect of $\mathrm{Cx}$ genes has been obtained by transfection of the genes into non-communicating tumor cells (10). In the transfected tumor cells, Cx genes conferred a reduced growth rate in culture as well as in nude mice. Recent studies including our report have suggested that not all $\mathrm{Cx}$ genes are able to exert a tumor-suppressive effect on a given tumor, but rather there seems to be a Cx-cell type compatibility for this effect $(11,12)$. That is, Cx exerts growth control only in tissues or cell types in which the particular $\mathrm{Cx}$ is naturally expressed. In addition to $\mathrm{Cx} 43$, it has been demonstrated that Cx32 is mostly down-regulated in lung adenocarcinoma and that this Cx acts as a tumor suppressor in a mouse model of human lung adenocarcinoma $(13,14)$. However, the tumorsuppressive effect of Cx32 compared with the suppressive effect of Cx43 on lung cancer remains to be clarified. (15).

In a recent report, it has been demonstrated that the protooncogene product, pp60c-src (Src), which is a member of the non-receptor tyrosine kinase, is activated in lung adenocarcinoma and that the activation plays a critical role in the progression of the adenocarcinoma (16). A previous report has suggested that inhibition of GJIC by $\operatorname{src}$ gene product is required for cell transformation (17). On the contrary, we have recently reported that $\mathrm{Cx} 32$ reduces the appearance of malignant phenotypes in renal cell carcinoma cells via the inactivation of Src (18). Collectively, these reports suggest that re-expression of Cx32 induces the inactivation of Src, leading to attenuation of malignant phenotypes in lung adenocarcinoma cells. The present study was undertaken to examine this hypothesis.

\section{Materials and methods}

Cell culture and treatment. A549, a human lung adenocarcinoma cell line was obtained from Riken cell bank 
(Saitama, Japan), and maintained in media and culture conditions as described. The cells were cultured in DMEM medium (Invitrogen, San Diego, CA) supplemented with $10 \%$ fetal calf serum (FCS) and penicillin-streptomycin on standard plastic tissue culture dishes and incubated in an atmosphere of $95 \%$ air $/ 5 \% \mathrm{CO}_{2}$ at $37^{\circ} \mathrm{C}$. PP1 (BIOMOL, Plymouth Meeting, PA) and PP3 (Calbiochem, La Jolla, CA) were used as an Src inhibitor and a negative control of PP1, respectively. A549 cells have invasive and metastatic phenotypes (19), and we confirmed that they have no expression of the Cx32 and $\mathrm{Cx} 43$ genes (unpublished data). Therefore, we selected this cell line to perform this study.

Constructs and transfect. The human Cx32 cDNA insert containing the entire coding region (18) was subcloned into the expression vector pcDNA3 (Invitrogen) at the KpnI-BamHI site, and the sequence of construct pcDNA3-Cx32 was confirmed by DNA sequencing. Parental cells were transfected with either $3 \mu \mathrm{g}$ of $\mathrm{Cx} 32 \mathrm{cDNA}$ or empty pcDNA3 vector, as a control using Gene Jamar transfect reagent (Stratagene, La Jolla, CA). After $48 \mathrm{~h}$, the cells were selected in culture medium containing $0.8 \mathrm{mg} / \mathrm{ml} \mathrm{G} 418$ (Sigma, St. Louis, MO) for10 days. In order to avoid clonal variations by selection, we pooled all of the surviving clones and used the resulting heterogeneous population to examine the tumor-suppressive effects of $\mathrm{Cx} 32$.

Measurement of GJIC. To measure GJIC of the cells, 5\% neurobiotin (Vector Laboratories, Burlingame, CA) and $0.4 \%$ rhodamine dextran (Molecular Probes, Eugene, OR) in phosphate-buffered saline (PBS) was microinjected into a single cell (12). Dye transfer was quantified by counting the number of fluorescent cells surrounding an injected cell under a phase contrast and fluorescence microscope (Olympus, Tokyo, Japan). The average number of communicating cells was determined from 20 injections.

Estimate of saturation density and anchorage-independent cell growth. Cells $\left(3 \times 10^{4}\right)$ were seeded on a $60-\mathrm{mm}$ culture dish with the culture medium at day 0 of the experiment. Saturation density was determined by counting cell numbers at day 10 of the experiment. Anchorage independency was performed in soft agar as described previously (20). Briefly, $1 \times 10^{4}$ cells were seeded in $2 \mathrm{ml}$ culture medium containing $0.3 \%$ agar on a solidified $(0.5 \%$ agar) basal layer $(3 \mathrm{ml})$ in the same medium in 6-well plates. Three wells were prepared for each cell group. Two weeks after seeding, colonies containing at least 20 cells were counted. The cells were seeded in triplicate in all experiments.

Tumorigenicity assay in nude mice. Aliquots of $1 \times 10^{7}$ cells of each cell group in Matrigel (BD Biosciences, Bedford, MA) were subcutaneously injected into the backs of three 5week-old BALB/c An-nu/nu athymic mice (Japan Clea, Tokyo, Japan). At week 4 after subcutaneous injection, tumors were carefully removed after sacrificing the mice and then weighed.

Estimation of invasive capacity. Invasion assay was performed essentially as described previously using a Matrigel invasion chamber (Becton Dickinson, Bedford, MA) (21). The ability of the cells to invade the substratum was tested by using an established growth factor for epithelial cells, epidermal growth factor $(21)$. The invasion index $(\%)$ was determined as the number of invasive cells divided by the number of invasive and non-invasive cells x 100 .

Immunoblot analysis. Anti-Cx32 and anti- $\beta$-actin were purchased from Sigma. Anti-E-adherin, anti- $\alpha$-catenin, and anti- $\beta$-catenin were obtained from Cell Signaling Technology (Beverly, MA). Immunoblot anlysis was performed as previously described (12). Briefly, cell lysate was prepared in cell lysis extraction reagent (Sigma), and $20 \mu \mathrm{g}$ total protein extract from each sample was loaded onto $5 \%$ or $10 \%$ SDSpolyacrylamide gel. After electrophoresis, proteins were transferred to nitrocellulose membranes. The blots were incubated with each primary antibody. Each immunoreactive band was detected using the ECL system (Amersham, UK) and a cooled CCD camera-linked Cool Saver system (Atto, Osaka, Japan). Molecular sizing was performed using a Rainbow MW marker (Amersham). Protein concentrations were determined using DC protein assay system (Biorad, Hercules, CA).

Estimation of Src activity. The cells were plated in 6-well plates in culture medium for $24 \mathrm{~h}$, lysed and immunoprecipitated with anti-Src antibody as described previously. The immuno-complex was used as an enzyme source to determine Src activity. The reaction mixture contained Src immuno-complex, $250 \mathrm{ng}$ poly $\left(\mathrm{Glu}_{4}\right.$-Tyr $)$ peptide-biotin conjugate, $10 \mathrm{mM} \mathrm{MgCl}, 1 \mathrm{mM} \mathrm{MnCl} 2,1 \mathrm{mM}$ Dithiothreitol, $200 \mu \mathrm{M}$ ATP, and $20 \mathrm{mM}$ Tris-HCl buffer (pH 7.4), and the reaction was performed at $37^{\circ} \mathrm{C}$ for $15 \mathrm{~min}$. After the reaction, Src activity was estimated by enzyme-linked immunosorbent assay (ELISA) using the tyrosine kinase assay kit for chemiluminescent detection (Upstate, Charlottesville, VA, USA), according to the manufacturer's instructions.

siRNA treatment. The Cx32 gene was down-regulated by siRNA for Cx32 (Qiagen, MD, USA) as previously described (18). In brief, Cx32-transfected A549 cells (A549-Cx32) were seeded into 6-well plates $24 \mathrm{~h}$ prior to transfection with siRNA (4 $\mu \mathrm{g} /$ plate), and the transfection was carried out in a $70 \%$ confluent status. At $48 \mathrm{~h}$ after siRNA treatment, the expression level of Cx32 protein was determined by immunoblot analysis, and Src activity was measured as mentioned above.

Isolation of total RNA and real-time PCR. Total RNA was isolated by using an SV Total RNA isolation system (Promega, Madison, WI, USA) and cDNA was synthesized as previously described (12). Real-time PCR was performed by using an ABI PRISM 7000 sequence detection system (Applied Biosystems Japan Ltd., Tokyo, Japan) and SYBR Premix Ex Taq ${ }^{\mathrm{TM}}$ (TaKaRa Bio Inc., Shiga, Japan) according to the manufacturers' instructions. The primers used were: glycer-aldehyde-3-phosphate dehydrogenase (GAPDH), accession no. (BC023632), sense (nucleotides 737-756), antisense (nucleotides 916-897); PAI-1, accession no. (M16006), sense (nucleotides 887-905), anti-sense (nucleotides 1012-991); uPA, accession no. (BC013575), sense (nucleotides 1672- 

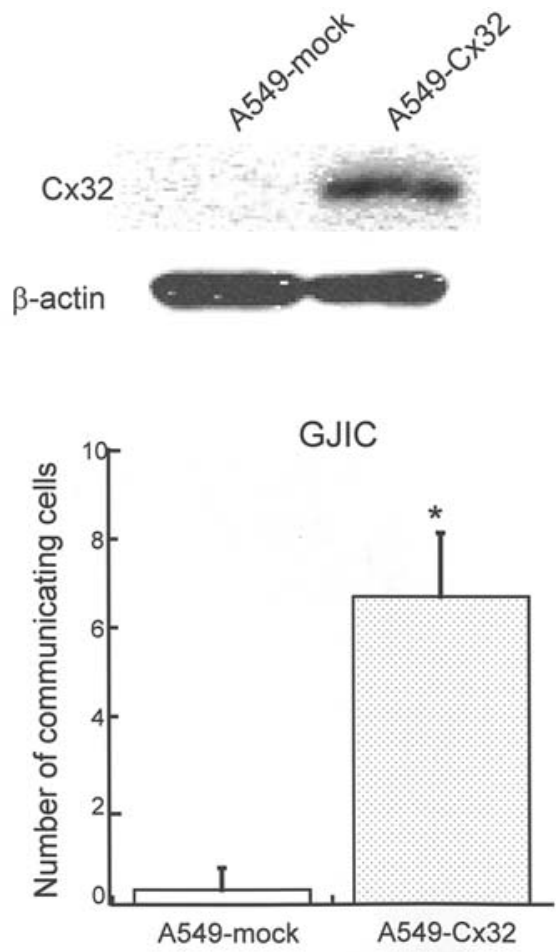

Figure 1. Immunoblot analysis of Cx32 level and GJIC capacity in A549mock (mock-transfected A549 cells) and A549-Cx32 (Cx32-transfected A549 cells). The results of the the immunoblot analysis are representative of three independent experiments. GJIC capacity was estimated by a dye (neurobiotin) transfer assay. Each column represents the mean from 20 determinants and vertical lines indicate SE. *Significant difference from A549-mock.

1690), anti-sense (nucleotides 1847-1828); and uPAR, accession no. (BC002788), sense (nucleotides 529-549), antisense (nucleotides 698-678).

Statistical analysis. Data were analyzed by one-way ANOVA followed by Student's t-test or Dunnett's multiple-range test. $P$ values $\leq 0.05$ were considered significant.

\section{Results}

In order to elucidate the tumor-suppressive mechanism of Cx32 against lung adenocarcinoma cells, we transfected human Cx32 cDNA into a human lung adenocarcinoma cell, A549, which lacked endogenous Cx32. Initially, we checked the expression of $\mathrm{Cx} 32$ and the restoration of GJIC capacity in A549 cells. As shown in Fig. 1, in mock-transfected A549 cells (A549-mock), the expression of Cx32 was not detected and the GJIC was extremely low. However, we confirmed the expression of $\mathrm{Cx} 32$ as well as the restoration of GJIC capacity in the transfected cells (A549-Cx32). These results suggest that the expression of $\mathrm{Cx} 32$ relates to the restoration of GJIC capacity in A549 cells. Next, we examined the tumor-suppressive effects of $\mathrm{Cx} 32$ in vitro as well as in vivo. Cx32 reduced not only anchorage-independent growth but also the development of tumor in a xenograft model using nude mice (Fig. 2). These results indicate that Cx32 acts as a tumor-suppressor gene against A549 cells.

\section{a}

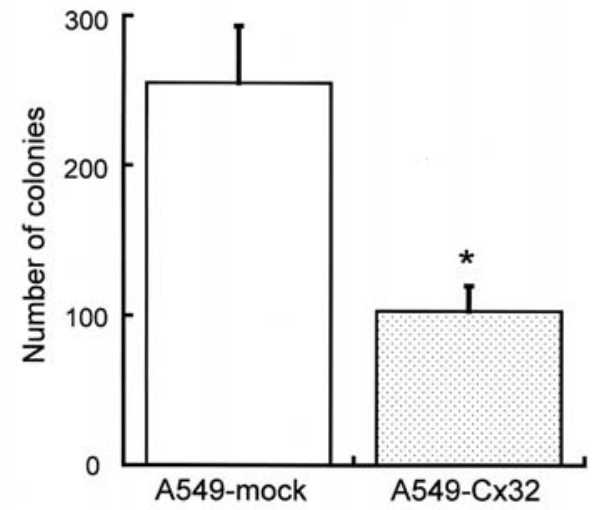

b

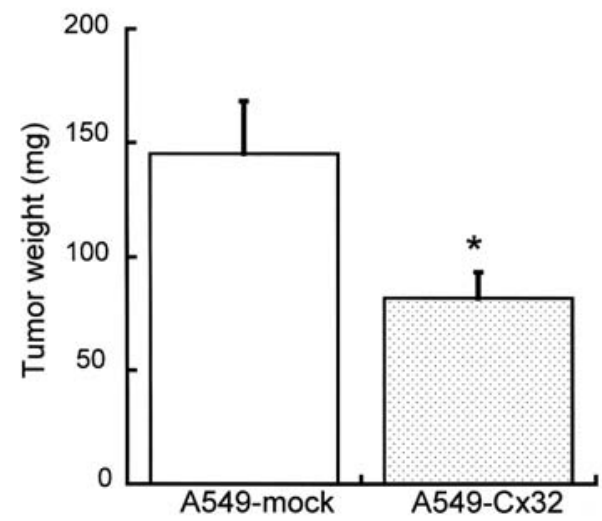

Figure 2. Anchorage-independent growth (a) and tumor weight in nude mice at week 4 after inoculation of A549 cells (b). Each assay was performed as described in Materials and methods. Values are expressed as means from three determinants, and each bar indicates SE. *Significant difference from A549-mock.

We have reported that $\mathrm{Cx} 32$ acts as a tumor-suppressor gene in renal cell carcinoma via the inactivation of Src (18), and the activation of Src is a critical step to induce the appearance of malignant phenotypes in lung adenocarcinoma cells including A549 cells $(16,19,22)$. From these reports, we examined if the inactivation of Src could contribute to the tumor-suppressive effect of Cx32 on A549 cells. First, we checked the effect of Cx32 on Src activity in A549 cells. As shown in Fig. 3a, the expression of Cx32 reduced Src activity in A549 cells with a statistical significance. On the contrary, Src activity in A549-Cx32 was significantly increased under silencing of Cx32 by siRNA treatment (Fig. 3b). These results suggest that Cx32 reduces Src activity in A549 cells. It is well known that the reduction of contact inhibition and increase of invasive capacity are typically malignant phenotypes of cancer cells $(20,23)$ and that the activation of Src is associated with the appearance of such malignant phenotypes (24). Thus, finally, we investigated if Cx32 could suppress the appearance of the two malignant phenotypes in A549 cells via the inactivation of Src. As shown in Fig. 4a, the expression of $\mathrm{Cx} 32$ as well as the inhibition of Src activity 
a

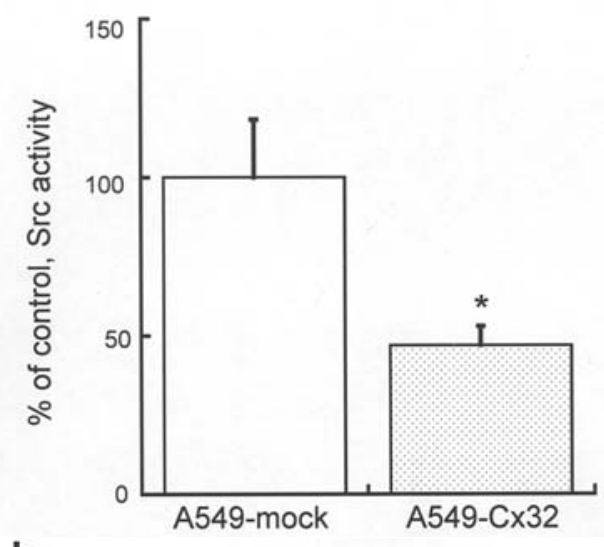

b

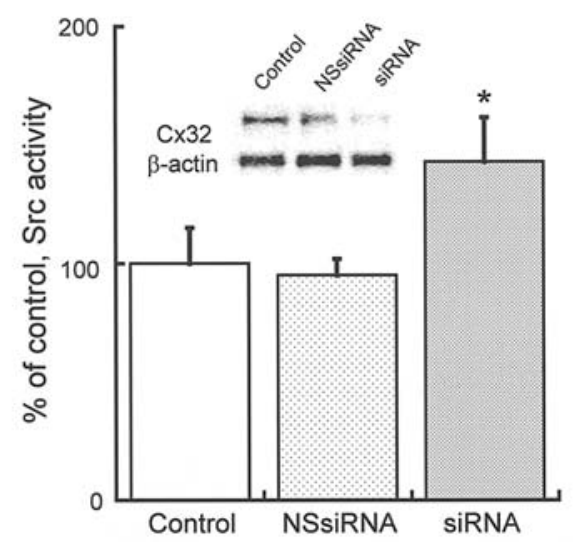

Figure 3. Src activity in A549-mock and A549-Cx32 (a), and in A549-Cx32 under silencing of Cx32 by siRNA (b). (a) After culture for $24 \mathrm{~h}, \mathrm{Src}$ activity was determined as described in Materials and methods. Values are expressed as the means from three determinants, and each bar indicates SE. "Significant difference from A549-mock. (b) The cells were treated with siRNA (Cx32) for $48 \mathrm{~h}$, and subsequently Src activity and Cx32 protein level were determined as described in Materials and methods. Control, nontreated A549-Cx32; NSsiRNA, non-specific control siRNA-treated A549Cx32; siRNA, siRNA for Cx32-treated A549-Cx32. The result of Cx32 protein level is representative of two independent experiments. Values for Src activity are expressed as means from three determinants, and each bar indicates SE. "Significant difference from control and NSsiRNA.

by PP1 in A549 cells led to a reduction of saturation density, that is, restoration of contact inhibition. It has been reported that the restoration of E-cadherin-driven adherence junctions relates to a gain of contact inhibition in cancer cells (25), so we hypothesized that the restoration of adherence junctions by $\mathrm{Cx} 32$ contributes to the gain of contact inhibition. As expected, Cx32 expression in A549 cells increased the protein levels of the adherence junction molecules, E-cadherin, $\alpha$-catenin and B-catenin (Fig. 4b). Similarly, forced inhibition of Src in A549 cells led to elevations of the same molecules (Fig. 4b). These results suggest that Cx32-dependent inhibition of Src in A549 cells plays an important role in the restoration of contact inhibition based on the gain in molecules necessary for adherence junctions. As well as the effect on contact inhibition, the Cx32 expression and the $\mathrm{Src}$ inhibition suppressed invasive capacity in A549 cells with a a

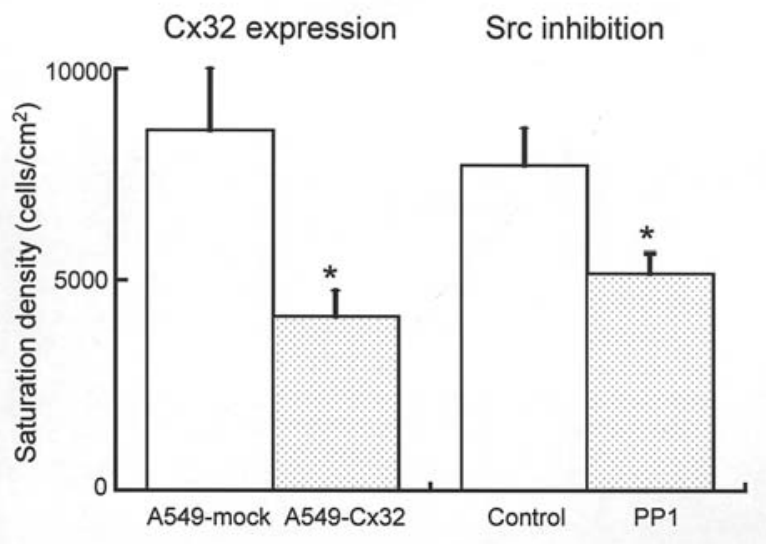

b

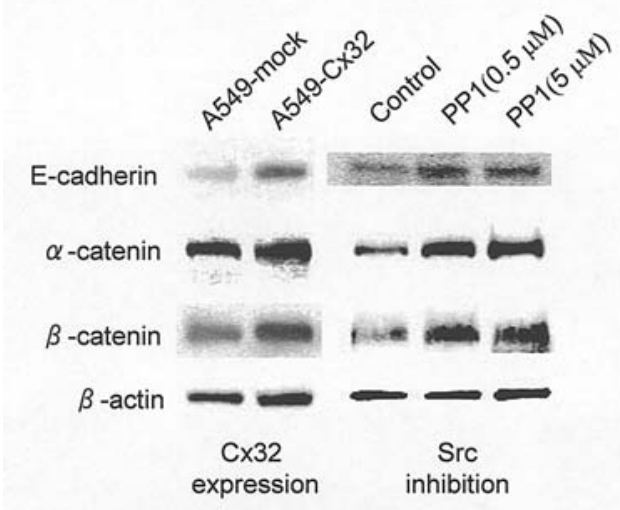

Figure 4. Saturation density in Cx32 expression and Src inhibition of A549 cells (a) and inducing effects of $\mathrm{C} \times 32$ and Src inhibition on cell adhesion molecules in A549 cells (b). (a) Saturation density was determined as described in Materials and methods. In the Src inhibition experiment, we used PP1 as an Src inhibitor. Non-transfected A549 cells (A549-mock) were treated with PP1 $(0.5 \mu \mathrm{M})$ for 10 days, and subsequently the saturation density was measured. Values are expressed as means from three determinants, and each bar indicates SE. *Significant difference from A549mock. (b) A549 cells were treated with PP1 at indicated concentrations for $24 \mathrm{~h}$, and subsequently each protein level was determined as described in Materials and methods. The result of each protein level is representative of two independent experiments.

statistical significance (Fig. 5a). Since up-regulations of the fibrinolytic factors have important roles in the invasion of cancer cells (26), we determined the influences of Cx32 and Src on the fibrinolytic system, namely urokinase-type plasminogen activator (UPA), uPA receptor (uPAR) and type-I plasminogen activator inhibitor (PAI-1) in A549 cells. As shown in Fig. $5 b$ and c, both the Cx32 expression and the Src inhibition induced a reduction of mRNA level of each fibrinolytic factor, indicating that $\mathrm{Cx} 32$-dependent inactivation of Src led to the suppression of invasive capacity in A549 cells via the regulation of the fibrinolytic system.

\section{Discussion}

Over-expression and activation of Src have been identified in a range of human cancers and have played central roles in the appearance of malignant phenotypes of these cancers (27). 
a

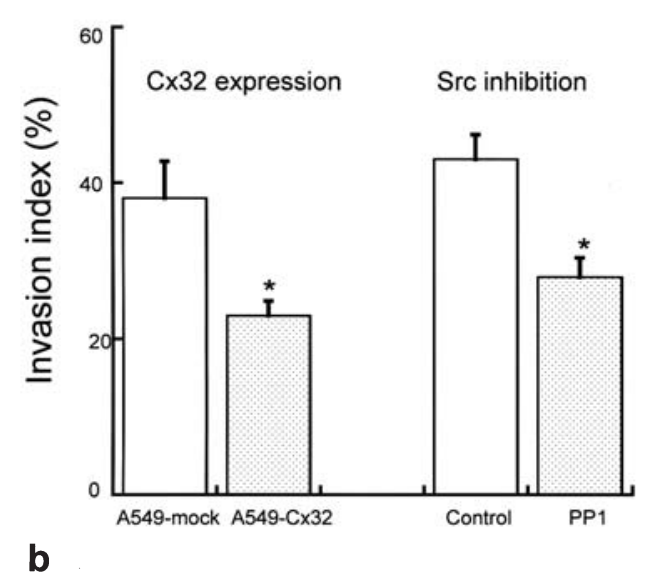

Cx32 expression

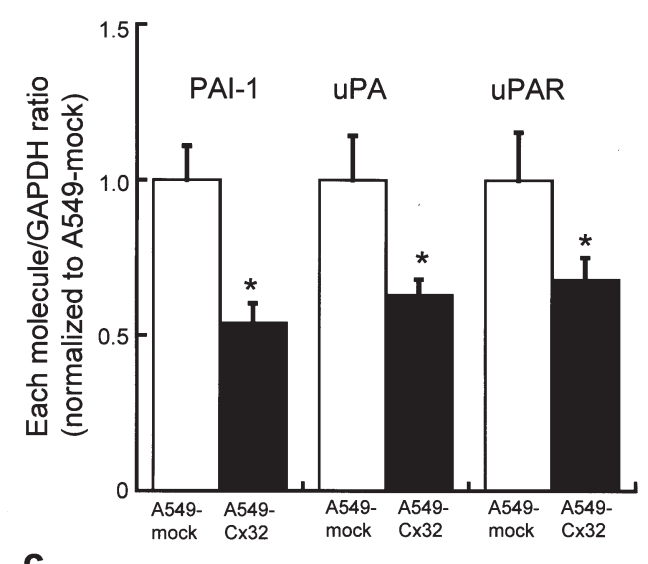

Src inhibition

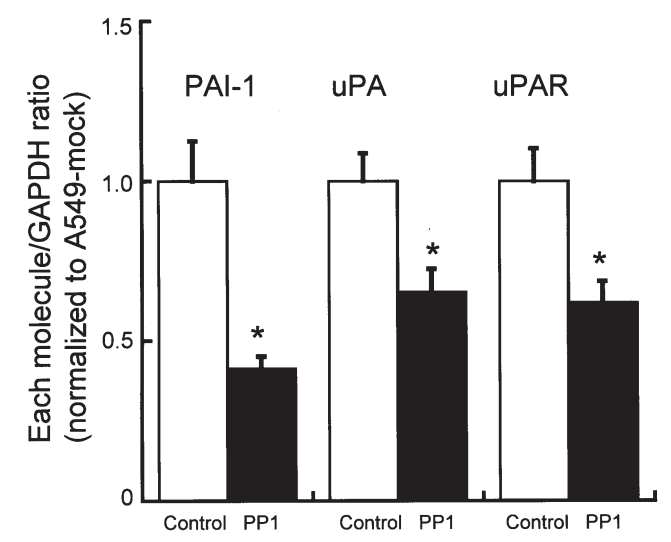

Figure 5. Suppressive effect of Cx32 or Src inhibition on cell invasion capacity (a) in A459 cells, and influence of Cx32 (b) or Src inhibition (c) on expression of fibrinolytic factors' mRNAs in the cells. (a) Cell invasion capacity was estimated as described in Materials and methods. The cells were pretreated with PP1 $(0.5 \mu \mathrm{M})$ for $24 \mathrm{~h}$, and subsequently the invasion assay was carried out. Values are expressed as means from three determinants, and each bar indicates SE. *Significant difference from A549mock or control. (b) Each mRNA level was determined as described in Materials and methods. Values are expressed as means from three determinants, and each bar indicates SE. *Significant difference from A549mock. (c) The cells were treated with PP1 $(0.5 \mu \mathrm{M})$ for $24 \mathrm{~h}$, and subsequently the mRNA level was measured as described in Materials and methods. Values are expressed as means from three determinants, and each bar indicates SE. *Significant difference from control.
Especially, the activation of Src stimulates invasion and metastasis in cancer more than primary cancer cell growth (28), because Src induces invasive and metastatic phenotypes of cancer cells due to up-regulation of several signal molecules governing invasion and metastasis (29). Thus, Src inhibition may be useful for the prevention of invasion and metastasis in cancer (28). In fact, we have shown that the inactivation of Src by Cx32 down-regulates vascular endothelial growth factor as an inducer of angiogenesis (20) and fibrinolytic factors as important causal mechanisms of invasion (30), leading to antiinvasive and anti-metastatic effects of $\mathrm{Cx} 32$ on metastatic renal cell carcinoma cells. Also, in this study, we demonstrated that the expression of Cx32 in A549 cells restored contact inhibition via the up-regulation of cell adhesion molecules such as E-cadherin and abrogated invasive capacity due to reduction of fibrinolytic activity. Taken together, it seems that Cx32 acts as a tumor-suppressor gene against A549 cells due to the reduction of malignant invasive and metastatic phenotypes by the inactivation of Src.

In a recent review (31), it has been proposed that Cxs and their GJ control cellular homeostatic balance mainly via two communicative networks: a) intracellular communication; $\mathrm{Cx}$ proteins affect the gene expression of homeostasis regulatory proteins, b) intercellular communication (GJIC); GJ mediates passage of signaling molecules between neighboring cells. In the present study, Cx32 suppresses several molecules related to invasion and metastasis of A549 cells via the inactivation of Src (intracellular communication), leading to the restoration of normal cellular signal networks in the cells. Subsequently, Cx32-driven GJIC induces restoration of normal homeostatic balance via propagation of normal signaling between neighboring cells. Thus, a combination of Cx32-dependent intracellular and intercellular communication contributes to the potential function of the $\mathrm{Cx}$ as a tumorsuppressor gene against A549 cells. In addition to the combination effect of $\mathrm{Cx} 32$, GJIC driven by $\mathrm{Cx}$ is required for effective induction of apoptosis (32). Since the onset of apoptosis is generally associated with drastic alterations in $\mathrm{Ca}^{2+}$ concentration, $\mathrm{Ca}^{2+}$ ions, which are intercellularly exchanged via GJ, are thought to be 'killing messengers', thus spreading the death wave from cell to cell $(33,34)$. This propagation of the death wave via GJIC can amplify anticancer agent-induced cytotoxic effects on cancer cells, leading to the enhancement of therapeutic efficacy on cancer by anti-cancer agents (35). We have observed that Cx32 suppresses the in vitro and in vivo growth of metastatic renal cancer cells by the combination of intracellular and intercellular communication mechanisms (20) and that GJIC mediated by $\mathrm{Cx} 32$ potentiates chemotherapeutic agentinduced apoptosis in cancer cells (36). Lung adenocarcinoma cells including A549 cells are relatively chemoresistant to several types of anti-cancer agents (37), so the above communicative mechanisms mediated by $\mathrm{Cx} 32$ may be effective in overcoming chemoresistance in lung cancer. In fact, we observed that the expression of Cx32 in A549 cells enhanced chemotherapeutic agent-induced cytotoxicity in vitro (unpublished data). Should this observation be effective in clinical usage, Cx32-mediated communicative mechanisms may be useful to establish a new therapy against lung adenocarcinomas. 


\section{Acknowledgements}

This study was supported by a research grant for Health Sciences Focusing on Drug Innovation from the Japan Health Sciences Foundation (KH21012).

\section{References}

1. Mesnil M and Yamasaki H: Cell-cell communication and growth control of normal and cancer cells: evidence and hypothesis. Mol Carcinog 7: 14-17, 1993.

2. Stauffer KA, Kumar NM, Gilula NB and Unwin N: Isolation and purification of gap junction channels. J Cell Biol 115: 141-150, 1991.

3. Willecke K, Eiberger J, Degen J, Eckardt D, Romualdi A, Guldenagelb M, Deutsch M and Sohl G: Structural and functional diversity of connexin genes in the mouse and human genome. Biol Chem 383: 725-737, 2002

4. Paul DL: New functions for gap junctions. Curr Opin Cell Biol 7: 665-672, 1995 .

5. Fitzgerald DJ and Yamasaki H: Tumor promotion: models and assay systems. Teratog Carcinog Mutagen 10: 89-102, 1990.

6. Martin W, Zempel G, Hulser D and Willecke K: Growth inhibition of oncogene-transformed rat fibroblasts by cocultured normal cells: relevance of metabolic cooperation mediated by gap junctions. Cancer Res 51: 5348-5351, 1991.

7. Lowenstein WR and Kanno Y: Intercellular communication and the control of tissue growth: lack of communication between cancer cells. Nature 209: 1248-1249, 1966.

8. Yamasaki H and Naus CCG: Role of connexin genes in growth control. Carcinogenesis 17: 1199-1213, 1996.

9. Martyn KD, Kurata WE, Warn-Cramer BJ, Burt JM, TenBroek E and Lau AF: Immortalized connexin43 knockout cell lines display a subset of biological properties associated with the transformed phenotype. Cell Growth Differ 8: 1015-1027, 1997.

10. Rae RS, Mehta PP, Chang CC, Trosko JE and Ruch RJ Neoplastic phenotype of gap-junctional intercellular communication-deficient WB rat liver epithelial cells and its reversal by forced expression of connexin32. Mol Carcinog 22: 120-127, 1998

11. Mesnil M, Krutovskikh V, Piccoli C, Elfgang C, Traub O, Willecke $\mathrm{K}$ and Yamasaki $\mathrm{H}$ : Negative growth control of HeLa cells by connexin genes: connexin species specificity. Cancer Res 55: 629-639, 1995.

12. Yano T, Hernandez-Blazquez FJ, Omori Y and Yamasaki H: Reduction of malignant phenotype of HepG2 cell is associated with the expression of connexin 26 but not connexin 32 . Carcinogenesis 22: 1593-1600, 2001.

13. Jinn Y, Ichioka M and Marumoto F: Expression of connexin32 and connexin43 gap junction proteins and E-cadherin in human lung cancer. Cancer Lett 127: 161-169, 1998.

14. King TJ and Lampe PD: The gap junction protein connexin 32 is a mouse lung tumor suppressor. Cancer Res 64: 7191-7196, 2004.

15. Ruch RJ, Cesen-Cummings K and Malkinson AM: Role of gap junctions in lung neoplasia. Exp Lung Res 24: 523-539, 1998.

16. Masaki T, Igarashi K, Tokuda M, Yukimasa S, Han F, Jin YJ, Li JQ, Yoneyama H, Uchida N, Fujita J, Yoshiji H, Watanabe S, Kurokohchi $\mathrm{K}$ and Kuriyama S: pp60 ${ }^{\text {c-src }}$ activation in lung adenocarcinoma. Eur J Cancer 39: 1447-1455, 2003.

17. Chang CC, Trosko JE, Kung HJ, Bombick D and Matsumura F: Potential role of the src gene product in inhibition of gapjunctional communication in NIH/3T3 cells. Proc Natl Acad Sci USA 82: 5360-5364, 1985.

18. Fujimoto E, Sato H, Shirai S, Nagashima Y, Fukumoto K, Hagiwara H, Negishi E, Ueno K, Omori Y, Yamasaki H, Hagiwara $\mathrm{K}$ and Yano T: Connexin 32 as a tumor suppressor gene in a metastatic renal cell carcinoma cell line. Oncogene 24: 3684-3690, 2005.
19. Yamaki T, Endoh K, Miyahara M, Nagamine I, Huong NTT, Sakurai H, Pokorny J and Yano T: Prostaglandin $\mathrm{E}_{2}$ activates Src signaling in lung adenocarcinoma cell via $\mathrm{EP}_{3}$. Cancer Lett 214: $115-120,2005$

20. Fujimoto E, Satoh H, Negishi E, Ueno K, Nagashima Y, Hagiwara K, Yamasaki H and Yano T: Negative growth control of renal cell carcinoma cell by connexin 32: possible involvement of Her-2. Mol Carcinog 40: 135-142, 2004.

21. Carloni V, Romanelli RG, Mercurio AM, Pinzani M, Laffi G, Cotrozzi G and Gentilini P: Knockout of alpha6beta1-integrin expression reverses the transformed phenotype of hepatocarcinoma cells. Gastroenterology 115: 433-442, 1998.

22. Song L, Turkson J, Karras JG, Jove R and Haura EB: Activation of Stat3 by receptor tyrosine kinases and cytokines regulates survival in human non-small cell carcinoma cells. Oncogene 22: 4150-4165, 2003.

23. Rao JS, Gondi C, Chetty C, Chittivelu S, Joseph PA and Lakka SS Inhibition of invasion, angiogenesis, tumor growth, and metastasis by adenovirus-mediated transfer of antisense uPAR and MMP-9 in non-small cell lung cancer cells. Mol Cancer Ther 4: 1399-1408, 2005.

24. Zheng R, Yano S, Matsumori Y, Nakataki E, Muguruma H, Yoshizumi $\mathrm{M}$ and Sone S: SRC tyrosine kinase inhibitor, M475271, suppresses subcutaneous growth and production of lung metastasis via inhibition of proliferation, invasion, and vascularization of human lung adenocarcinoma cells. Clin Exp Metastasis 22: 195-204, 2005.

25. Vizirianakis IS, Chen YQ, Kantak SS, Tsiftsoglou AS and Kramer RH: Dominant-negative E-cadherin alters adhesion and reverses contact inhibition of growth in breast carcinoma cells. Int J Oncol 21: 135-144, 2002.

26. Andreasen PA, Egelund R and Petersen HH: The plasminogen activation system in tumor growth, invasion, and metastasis. Cell Mol Life Sci 57: 25-40, 2000.

27. Frame MC: Src in cancer: Deregulation and consequences for cell behavior. Biochim Biophys Acta 1602: 114-130, 2002.

28. Nam JS, Ino Y, Sakamoto M and Hirohashi S: Src family kinase inhibitor PP2 restores the E-cadherin/catenin cell adhesion system in human cancer cells and reduces cancer metastasis. Clin Cancer Res 8: 2430-2436, 2002.

29. Irby RB and Yeatman TJ: Role of Src expression and activation in human cancer. Oncogene 19: 5636-5642, 2000.

30. Hagiwara H, Sato H, Shirai S, Kobayashi S, Fukumoto K, Ishida T, Seki T, Ariga T and Yano T: Connexin 32 downregulates the fibrinolytic factors in metastatic renal cell carcinoma cells. Life Sci (in press).

31. Vinken M, Vanhaecke T, Papeleu P, Snykers S, Henkens T and Rogiers V: Connexins and their channels in cell growth and cell death. Cell Signal (in press).

32. Kalvelyte A, Imbrasaite A, Bukauskiene A, Verselis VK and Bukauskas FF: Connexins and apoptotic transformation. Biochem Pharmacol 66: 1661-1672, 2003.

33. Krysko DV, Mussche S, Leybaert L and D'Herde K: Gap junctional communication and connexin43 expression in relation to apoptotic cell death and survival of granulosa cells. J Histochem Cytochem 52: 1199-1207, 2004.

34. Krutovskikh VA, Piccoli C and Yamasaki H: Gap junction intercellular communication propagates cell death in cancerous cells. Oncogene 21: 1989-1999, 2002.

35. Trosko JE and Ruch RJ: Gap junctions as targets for cancer chemoprevention and chemotherapy. Curr Drug Targets 3: 465-482, 2002.

36. Fujimoto E, Sato H, Nagashima Y, Negishi E, Shirai S, Fukumoto E, Hagiwara H, Hagiwara K, Ueno $\mathrm{K}$ and Yano T: A Src family inhibitor (PP1) potentiates tumor-suppressive effect of connexin 32 gene in renal cancer cells. Life Sci 76: 2711-2720, 2005.

37. Shivapurkar N, Reddy J, Chaudhary PM and Gazdar AF: Apoptosis and lung cancer: a review. J Cell Biochem 88: 885-898, 2003 . 